\title{
Hemagglutination inhibition antibody titers as a correlate of protection against influenza disease in the 2018/2019 epidemic season in Poland
}

\author{
Ewelina Hallmann-Szelińska®, Karol Szymański, Katarzyna Łuniewska, Katarzyna Kondratiuk \\ and Lidia Bernadeta Brydak
}

Department of Influenza Research - National Influenza Center, National Institute of Public Health - National Institute of Hygiene, Warsaw, Poland

The aim of this study was to determine the level of antibodies against hemagglutinin of influenza viruses in the sera of people in the seven age groups in the epidemic season 2018/2019 in Poland. The level of anti-hemagglutinin antibodies was determined by hemagglutination inhibition assay (HAI). 1050 clinical samples from all over the country were tested. The level of antibodies against influenza viruses was highest in the 10-14 age group for A/Singapore/INFIMH-16-0019/2016 (H3N2) and B/Phuket/3073/2013 Yamagata lineage antigens. These results confirm the circulation of four antigenically different influenza virus strains, two subtypes of influenza A virus - A/Michigan/45/2015 (H1N1)pdm09 and A/Singapore/INFIMH-16-0019/2016 (H3N2) and two lineages of influenza B virus - B/Colorado/06/2017 - Victoria lineage and B/Phuket/3073/2013 Yamagata lineage.

Key words: hemagglutinin antibodies, protection rate, influenza, GMT, vaccination

Received: 03 December, 2019; revised: 18 February, 2020; accepted: 25 February, 2020; available on-line: 17 March, 2020

囚e-mail: ehallmann@pzh.gov.pl

Acknowledgements of Financial Support: Funded by NIPH-NIH research subject $1 / \mathrm{EM}$

Abbreviations: $A$, hemaggutinin; $H A B$, hemagglutinin influenza $B_{i}$ $\mathrm{HAl}$, hemagglutination inhibition assay; GMT, geometric mean titer; NA, neuraminidase; NIC, National Influenza Centre; NIPH-NIH, National Institute of Public Health - National Institute of Hygiene; WHO, World Health Organization

\section{INTRODUCTION}

The influenza virus belongs to the Orthomyxoviridae family. In humans, infections are caused by types A, B, and $\mathrm{C}$ of the influenza virus, of which the first two are epidemiologically more important (Paules \& Subbarao, 2017).

Influenza accounts for three to five million severe cases and up to 650,000 deaths every year worldwide (WHO, 2019). Influenza viruses pose a threat to humans, especially those at high risk: people over 65 years of age; children under 2 years; pregnant women; people suffering from asthma, diabetes, cancer, or heart disease and people who stay permanently at home care or other long-term care facilities (CDC, 2019).

Due to its small size (diameter of about $80-120 \mathrm{~nm}$ ) and mass $\left(178-200 \times 10^{6} \mathrm{Da}\right)$, the influenza virus is able to spread by droplet transmission. The viral particles are released from the patient's body during sneezing or coughing and can move in the air for a distance of $2-3$ m (Paules et al., 2017; Brydak, 2008).
The genetic material of the influenza virus is a singlestranded RNA contained in a lipid-protein envelope. The genome of type $\mathrm{A}$ and $\mathrm{B}$ viruses consists of eight linear segments, while that of type $C$ virus consists of seven segments. The envelope of the influenza virus has a lipid bilayer in which two surface proteins are located: hemagglutinin (HA) (Fig. 1) and neuraminidase (NA). It also consists of two membrane proteins M1 and M2. The HA proteins belong to one of 18 types and NA to one of 11 types. Based on the amino acid sequences, influenza A viruses were divided into two phylogenetic groups. The first group has H1, H2, H5, H6, H8, H9, $\mathrm{H} 11, \mathrm{H} 12, \mathrm{H} 13, \mathrm{H} 16, \mathrm{H} 17$, and $\mathrm{H} 18$ proteins, while the second group has $\mathrm{H} 3, \mathrm{H} 4, \mathrm{H} 7, \mathrm{H} 10, \mathrm{H} 14$, and $\mathrm{H} 15$ proteins (Jang et al., 2019; Krammer et al., 2014).

$\mathrm{HA}$ is responsible for the adsorption of the viral molecule to the cell receptor in the host body. This glycoprotein can fuse to the cell membranes and facilitate the integration of the viral envelope with the membranes of the attacked cell, which in turn allows the virion to penetrate into the cytoplasm of the cell and release its internal structures (Brydak, 2008). HA constitutes 80\% of the total proteins in the viral envelope and is encoded by segment 4 of the viral genome. The protein has the form of a trimer, in which each monomer consists of a main spherical domain and a stem (Fig. 2). The respiratory proteases of the host are capable of cleaving HA into two subunits, HA1 and HA2, resulting in infection by the virus. These two subunits are joined together by disulfide bonds. The HA1 subunit acts as a binding site for the sialic acid moiety in the host receptor, and this part of the protein contains antigenic determinants (epitopes) against which the immune system of the host produces immunoglobulins during infection. By contrast, the HA2 subunit forms the transmembrane portion that anchors the protein in the lipid envelope of the virus and participates in the fusion between the viral envelope and the endosomal membrane. The amino acid sequence of the HA cleavage site differs, and the site is exposed by extracellular trypsin-like proteases located in the upper respiratory tract or in the digestive tract of the host. In this way, the virus causes local infection (Neumann et al., 2009).

When localized on the surface of the viral membrane, $\mathrm{HA}$ remains inactive (referred to as $\mathrm{HA} 0$ ). The protein becomes activated inside the endosome upon the exposure to reduced $\mathrm{pH}$ which changes its structure. X-ray studies showed that inside the endosome each of the three HA0 polypeptide chains is cleaved into two fragments by the host proteases. After cleavage, the two pro- 


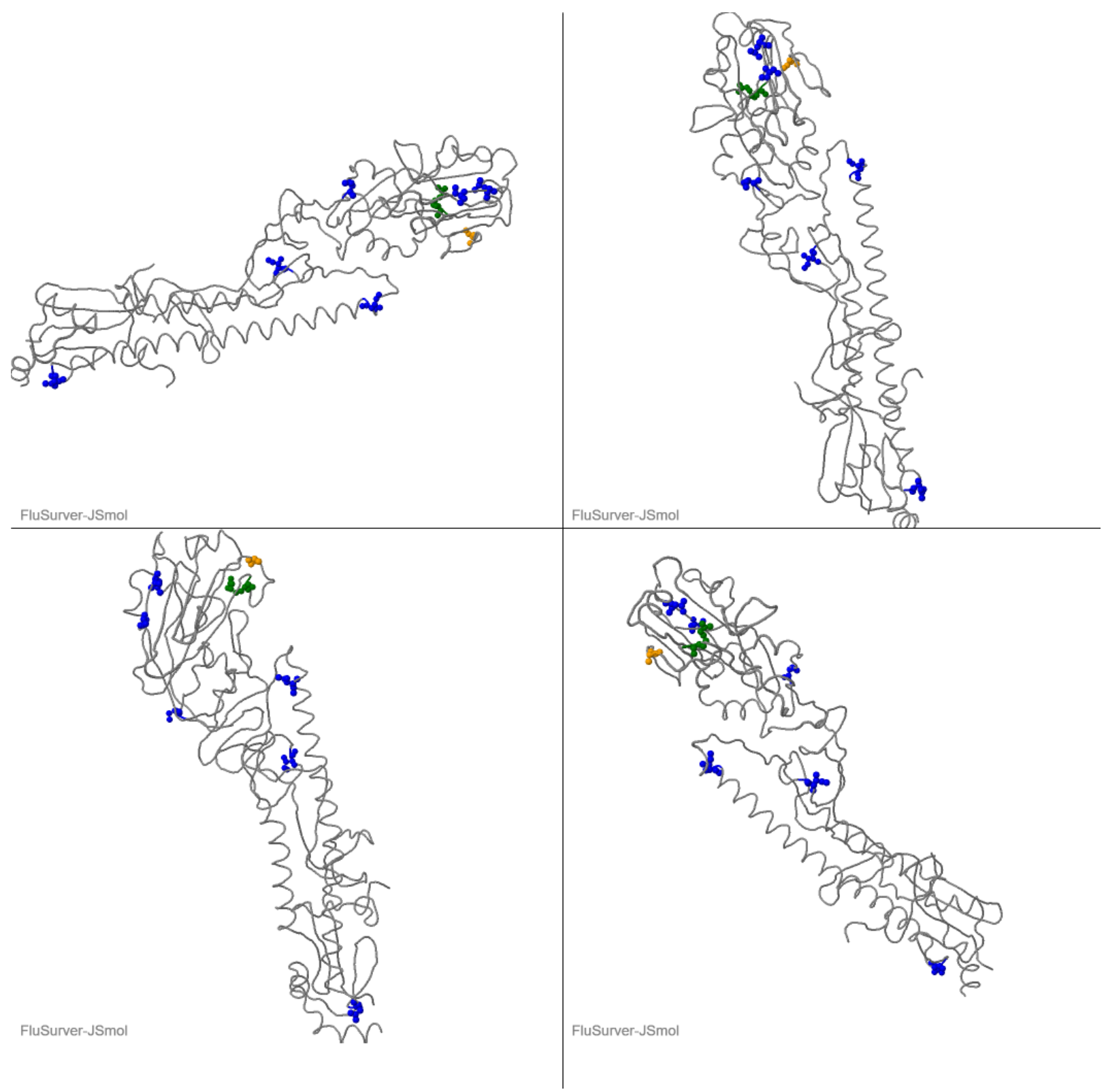

Figure 1. Hemagglutinin structure (https://flusurver.bii.a-star.edu.sg/). To create the image the sequence of influenza A virus (HA_H1N1_Human_2015_Michigan45) obtained from the Silesia Voivodeship was used. Mutations are marked in the diagram.

tein fragments (HA1 and HA2) formed are connected by a disulfide bridge. The HA2 fragment is referred to as a fusion peptide because it has the ability to bind to the endosomal membrane. This fusion fragment is exposed under favorable conditions and travels approximately 10 $\mathrm{nm}$ toward the endosomal membrane. Studies have also shown that acidification of the endosome and the rate of structural change of HA and exposure of the fusion peptide are temperature-dependent and proceed faster with the increase in temperature. This suggests that the typical response shown by an organism to fight the virus actually favors its faster infection (Webster, 2013; Sriwilaijaroen et al., 2012; Skehel et al., 2000).

Administration of the influenza vaccine leads to the production of specific antibodies. These immunoglobulins block the ability of the virus to adsorb to the host cells by attaching to the globular portion of its HA glycoprotein (Fig. 2). The level of these antibodies is measured using the HA inhibition assay (HAI). This test is carried out using chicken or turkey blood (Vemula et al., 2016; Kram- mer et al., 2014). The antibodies present in the blood bind to the shaft portion of the HA glycoprotein; however, these antibodies are rare in humans, and it is not possible to detect them and determine their titers using the HAI. In a person who received the vaccination, the produced immunoglobulins prevent the change in the conformation of the HA structure caused by the reduced $\mathrm{pH}$ in the endosome, thus disabling the virus from attaching to the cell (Krammer et al., 2014; Ekiert et al., 2010).

Antigenic shift, which is induced by collective immunity in the population as well as a decrease in the titer of the vaccine-specific antibody over time, necessitates the need for all-season vaccination. It is important to administer the vaccine before the virus increases in the population. However, a person can get vaccinated at any time during the season (ACIP, 2019; Houser et al., 2015). The effectiveness of the vaccine may vary between the seasons and also depends on the health and condition of the person receiving the vaccine. Nonetheless, regular vaccination reduces the negative effects of influenza in- 


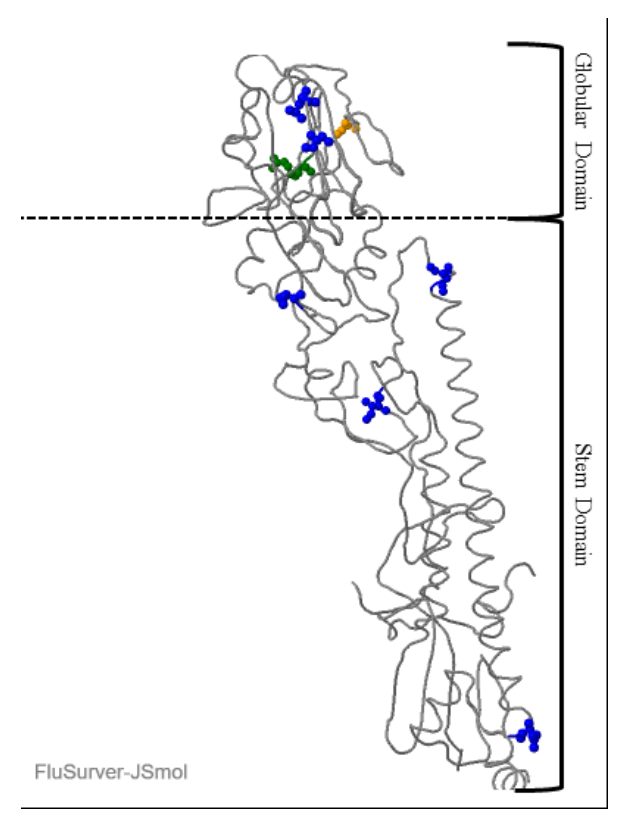

Figure 2. Hemagglutinin structure (https://flusurver.bii.a-star. edu.sg/). To create the image the sequence of influenza $A$ virus (HA_H1N1_Human_2015_Michigan45) obtained from the Silesia Voivodeship was used. Mutations are marked in the diagram.

fection. To date, the vaccination is considered the most effective way to prevent the infection by influenza viruses (WHO, 2019).

This study was performed to determine the level of anti-hemagglutinin (anti-HA) antibodies in the patients examined during the 2018/2019 epidemic season in Poland.

\section{MATERIALS AND METHODS}

The serum samples were collected from ambulatory patients who were $0-4,5-9,10-14,15-25,26-44,45-$ 64 , and $\geq 65$ years old by 16 Voivodship Sanitary Epidemiological Stations in Poland. The samples were stored at $-80^{\circ} \mathrm{C}$ until they were used for tests. Among the 1050 serum samples collected, 150 were tested for each age group. Antibody status was determined by HAI using eight HA units of the virus. Prior to performing the HAI, the sera were inactivated according to the standards (Tyrell \& Horsfall, 1952; WHO - Global Influenza Surveillance Network, 2011). The following parameters were analyzed: geometric mean titer (GMT) of the antihemagglutinin antibody in the tested sera and the protection rate (percentage of people with anti-hemagglutinin antibodies at a level $\geq 1: 40$ that appeared after the administration of an influenza vaccine or during the previous infection by the influenza virus) (Brydak, 2008).

The antigens listed in Table 1 were used in HAI in agreement with the WHO recommendations (WHO, 2018).

All antigens were propagated in chicken embryos and prepared in the Department of Influenza Research, Na- tional Influenza Centre (NIC) in the National Institute of Public Health-National Institute of Hygiene (NIPH$\mathrm{NIH}$ ), according to the WHO protocol (WHO - Global Influenza Surveillance Network, 2011). The preparation and dilution of the antigens for the HAI were performed in accordance with the WHO protocols (WHO - Global Influenza Surveillance Network, 2011).

\section{RESULTS}

GMTs of the anti-hemagglutinin antibody found in the sera collected from individuals of different age groups during the 2018/2019 epidemic season in Poland are shown in Fig. 3. According to the data analyzed for $\mathrm{H} 1$, the highest level of antibody was found among children. In the age group $0-4$ years, the level was 72.0, while in the age group 5-9 years it was 91.3. In the remaining age groups, the GMT values were below 40 . The lowest GMT for H1 was recorded in the age group 45-64 years (22.1 in the case of H3, the GMT was the highest in the age group 10-14 years, with a value of 104.8 , followed by the age group 5-9 years in which the GMT amounted to 50.8 and the age group 15-25 years in which GMT was 40.6. In the remaining age groups, GMT was at a similar level within 20-25.

Type B Yamagata HA had the highest GMT of all the HAs tested in the 10 to 14 years age group, with a value of 116.6 . In the age group $\geq 65$ years, GMT was 48.2, while in 45-64 years it was 43.3 and in 15-25 years it was 43.2. Among children in the age groups $0-4$ and 5-9 years, GMT values were similar at 35.3 and 35.5 , respectively. In the age group 26-44 years, GMT was the lowest with a value of 31.3 .

For type B Victoria lineage HA, the GMT of antibodies in all age groups was relatively low as follows: 0-4 years: 29.0 ; 5-9 years: 17.9 ; $10-14$ years: 30.0 ; 15-25 years: 15.9 ; 26-44 years: 28.8 ; $45-64$ years: 17.2 and $\geq 65$ years: 20.4 .

The protection rate is defined as the percentage of people with anti-hemagglutinin antibodies at a protection level of at least 1:40 after vaccination or infection (Brydak et al., 2003). The values of the protection coefficients for individual HAs of influenza virus strains in different age groups are presented in Fig. 4. It should be noted that for people over 60 years of age, the protection rate had a value of $\geq 60 \%$, while for people aged 18-60 years old it had a value of $\geq 70 \%$ (Brydak, 2008).

In the analyzed epidemic season, the highest protection levels were recorded for HAB strain B/ Phuket/3073/2013-like virus Yamagata lineage in the 10 to 14 years age group $(92.7 \%)$, followed by the age groups $\geq 65(74.0 \%), 45-64(71.3 \%)$, and $15-25$ years $(68.0 \%)$. In the age groups $0-4$ and $5-9$ years, a similar level of protection was achieved at $54.7 \%$ and $60.0 \%$, respectively. The lowest value of the protection coefficient was obtained for the age group 26-44 years at 47.3\%.

In the case of HAB strain B/Colorado/06/2017-like virus Victoria lineage the highest protection rate was recorded in the age group 10-14 years (47.3\%) and a lower value in the age group 26-44 years $(36.67 \%)$. On the other hand, the lowest level of the protection rate

Table 1. Influenza virus strains used for the hemagglutination inhibition test (HAI) in the 2018/2019 epidemic season.

\begin{tabular}{lllll}
\hline \multirow{2}{*}{$\begin{array}{l}\text { Epidemic } \\
\text { season } \\
2018-2019\end{array}$} & Influenza virus strains & & & \\
\cline { 2 - 5 } & A/H1N1/pdm09 & A/H3N2/ & B Victoria lineage & B Yamagata lineage \\
\cline { 2 - 5 } & $\begin{array}{l}\text { A/Michigan/45/2015 (H1N1) } \\
\text { pdm09-like virus }\end{array}$ & $\begin{array}{l}\text { A/Singapore/INFIMH-16-0019/2016 } \\
\text { (H3N2)-like virus }\end{array}$ & $\begin{array}{l}\text { B/Colorado/06/2017-like } \\
\text { virus }\end{array}$ & $\begin{array}{l}\text { B/Phuket/3073/2013-like } \\
\text { virus }\end{array}$ \\
\hline
\end{tabular}




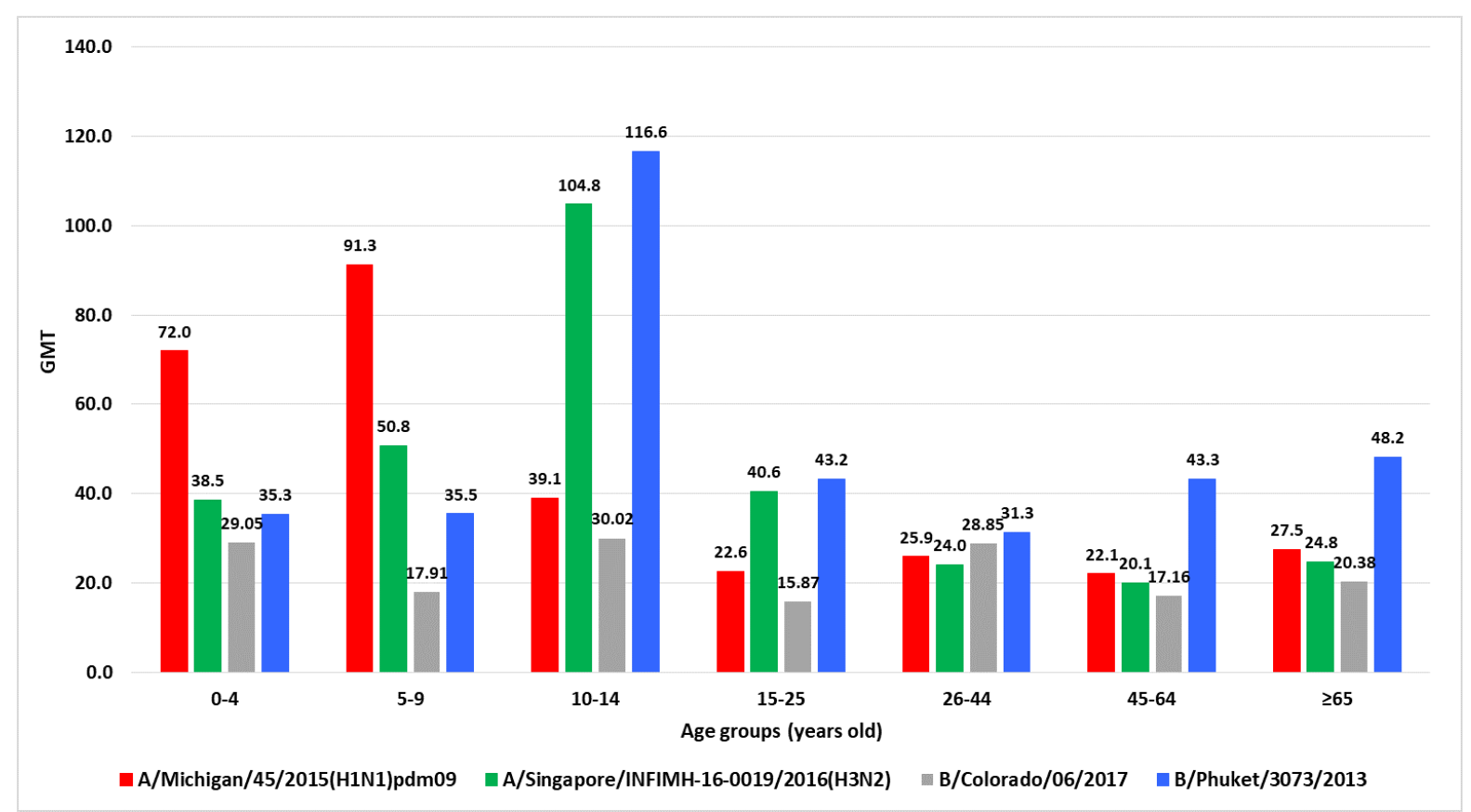

Figure 3. Geometric mean titers (GMT) of anti-hemagglutinin antibodies within the age groups in the 2018/2019 influenza epidemic season in Poland.

was recorded in the age groups $15-25$ and 45-64 years at $10.0 \%$. In the groups of younger children, the protection coefficient ranged from $22.67 \%$ ( $0-4$ years old) to $11.33 \%$ (5-9 years old) (Fig. 4). Among older people $\geq 65$ years old the protection rate was $12.67 \%$.

For H1 strain A/Michigan/45/2015(H1N1)pdm09like virus the highest protection level was observed in the age group $10-14$ years $(51.3 \%)$ and a lower level in the age group 5-9 years $(48.0 \%)$. In the remaining four age groups, the protection rate was at a similar level as follows: $0-4$ years: $20.0 \%$; $15-25$ years: $23.3 \%$; $26-44$ years: $24.0 \%$; and $\geq 65$ years: $14.7 \%$. The lowest protec- tion rate was recorded in the age group 45-64 years at $8.7 \%$.

For H3 strain A/Singapore/INFIMH-16-0019/2016 the protection rate was high among children: 10-14 years old: $91.3 \%$; 5-9 years old: $69.3 \%$ and $0-4$ years old: $51.3 \%$. In the age group 15-25 years, the value of the protection rate was $68.7 \%$. In the remaining age groups 26-44, 45-64, and $\geq 65$ years, the protection rate was between $21.0 \%$ and $35.0 \%$.

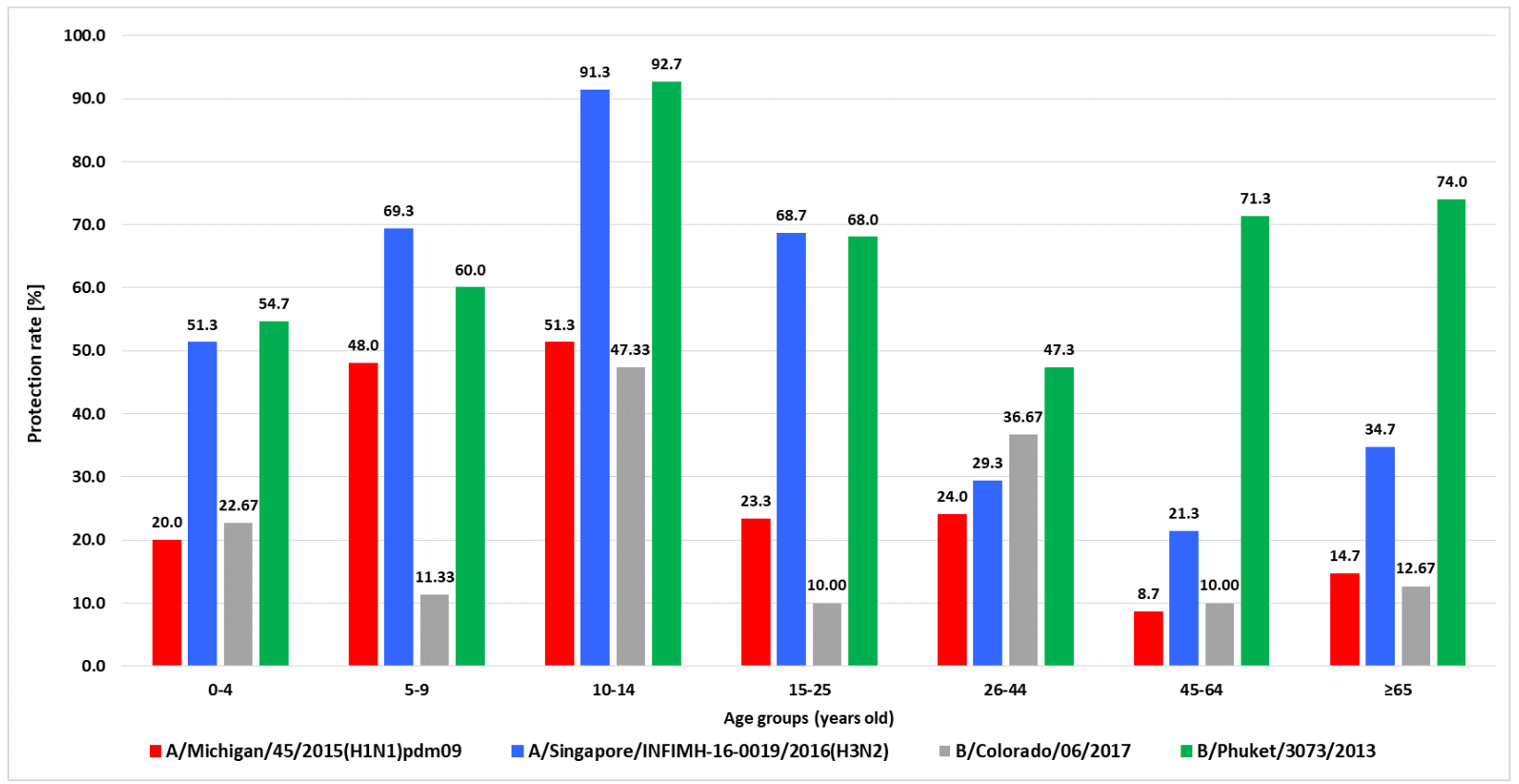

Figure 4. The proportion of individuals with a protective anti-hemagglutinin antibody titer level within the age groups in the 2018/2019 influenza epidemic season in Poland. 


\section{DISCUSSION}

In the 2017/2018 epidemic season, the influenza A/ $\mathrm{H} 1 \mathrm{~N} 1 / \mathrm{pdm} 09$ vaccine strain was changed from A/California/7/2009 to A/Michigan/45/2015 for the first time since the 2010/2011 epidemic season. The epidemic season 2018/2019 is, therefore, the second season in which this strain is included in the vaccine. The GMT values of strain A/Michigan/24/2015 in the analyzed season were higher among children in the age groups $0-4$ years $(72.0)$ and 5-9 years (91.3) compared to the previous season (0-4 years: 47.6 ; $5-9$ years: 51.1$)$. By analyzing the GMT values of the influenza A/H1N1/pdm09 strain from the $2013 / 2014$ epidemic season to the currently discussed $2018 / 2019$ season it was found that the GMT values of antibody titers were higher among the children of 0-14 years than in adults irrespectively of the type of strain contained in the vaccine (Hallmann-Szelińska et al., 2019; Kowalczyk et al., 2019; Hallmann-Szelińska et al., 2018; Kowalczyk et al., 2017; Bednarska et al., 2015). This may be due to the fact that children experience flu infections more frequently than adults (Glezen et al., 1980; Izurieta et al., 2000). According to the NIPH-NIH data, the incidence of infections by influenza and influenza-like viruses in the epidemic season 2018/2019 in children of 0-4 years of age was 59,417.5 and in the age group 5-14 years was $24,828.7$, while the incidence among adults of $15-64$ years of age was 8166.4 and in the age group $\geq 65$ years was 6650.9. In addition, it should be emphasized that the rate of vaccination against flu is very low in the Polish population. In 2018 , only $0.63 \%$ were vaccinated in the age group $0-4$ years, $0.96 \%$ in the $5-14$ years, $1.58 \%$ in the $15-64$ years, and $8.31 \%$ in the $\geq 65$ years. In the analyzed epidemic season, the protection rate was lowest for H1. Analyzing all the age groups, the lowest protection rate was observed in the 45-64 years group at $8.7 \%$, but in the previous season, it was $4.7 \%$ in the same group. However, the highest protection rate was found in the age group 10-14 years for all the HAs tested. In the 2017/2018 epidemic season, the highest values of the protection coefficient were recorded in the same age group at $38.0 \%$ for $\mathrm{H} 1$ and $74.7 \%$ for H3 (Hallmann-Szelińska et al., 2019), while the lowest values were recorded in the age group 45-64 years for four HAs and oscillated from $4 \%$ for $\mathrm{H} 3$ to $24.7 \%$ for B Yamagata lineage. By contrast, in the analyzed season, the lowest values of the protection rate were recorded in the age group 45-64 years at $8.7 \%$ for $\mathrm{H} 1$ and $21.3 \%$ for $\mathrm{H} 3$. For HAB Victoria, the protection rate was $10 \%$ in the age groups 15-25 and 45-64 years and was the lowest value recorded for this protein. The highest value of the protection rate was recorded for $\mathrm{H} 3$ at $91.3 \%$ and B Yamagata line at $92.7 \%$ in the age group $10-14$ years.

To summarize, the circulation of four strains of influenza virus contained in the vaccine for a given epidemic season was confirmed in Poland during the 2018/2019 epidemic season. For strain A/Michigan/45/2015 (H1N1) pdm09-like virus the highest levels of anti-hemagglutinin antibodies were detected in the age groups 0-4 years old and 5-9 years old. For strain A/Singapore/ INFIMH-16-0019/2016 (H3N2)-like virus the highest level of antibodies was recorded in the age group 1014 years. Whereas, for influenza B type, for strain B/ Colorado/06/2017-like virus Victoria lineage the level of anti-hemagglutinin antibodies was at a similar level in the age groups: 0-4 years, 10-14 years, 26-44 years and not gaining a protection value (value under 40). For strain B/Phuket/3073/2013-like virus Yamagata lineage a protection value of antibody titers was obtained in the $10-14$ years age group.

A study by Argentinean scientists showed that vaccination with proteins leads to CD4 T-cells and infection recalls their memory. In addition, the hemagglutinin released by infected or dying cells, rather than infectious virions, is the main source of antigen for antigen presentation after the infection (Knowlden, et al. 2019).

Reflecting the prevailing virological and epidemiological situation is possible thanks to the supervision of influenza, in which clinical samples are obtained from all over the country. Surveillance provides the information on the evolution of viruses and the correlation between antigenic differences and changes in sialic acid receptor binding properties of the HA glycoprotein. As a result of the mutation preventing the antibody from binding, may also be observed changes in sialic acid receptor binding (Lin, et al. 2012). In addition allows the selection of vaccine strains for the next epidemic season and monitoring the appearance of new variants, as well as checking the drug resistance of influenza viruses.

\section{Acknowledgments}

We acknowledge physicians and employees of Voivodship Sanitary Epidemiologic Stations, participating in the SENTINEL and NON-SENTINEL programs for their input into the influenza surveillance in Poland.

We would like to thank the Malec Company for providing fertilized chicken embryos.

\section{Conflicts of Interest}

The authors declare no conflicts of interest in relation to this article.

\section{REFERENCES}

Advisory Committee on Immunization Practices (2019) https://www. cdc.gov/mmwr/volumes/68/rr/rr6803a1.htm (Accesed 31.10.2019)

Bednarska K, Nowak MA, Kondratiuk K, Hallmann-Szelińska E, Brydak LB (2015) Incidence of circulating antibodies against hemagglutinin of influenza viruses in the epidemic season 2013/2014 in Poland. Adv Exp Med Biol 857: 45-50. https://doi. org $/ 10.1007 / 55842015118$

Brydak LB (2008) Influenza, pandemic flu, myth or real threat? Rythm Warsaw 1-492

Brydak LB (2012) Influenza - an age old problem. Hygeia Public Health 47: $1-7$

European Centre for Disease Prevention and Control (ECDC) (2019) https://www.cdc.gov/flu/highrisk/index.htm (Accesed, 28.10.2019)

European Centre for Disease Prevention and Control (ECDC) (2019) https://www.ecdc.europa.eu/en/seasonal-influenza/facts/factsheet (Accesed 28.10.2019)

Ekiert DC, Bhabha G, Elsliger MA, Friesen RH, Jongeneelen M, Throsby M, Wilson IA (2009) Antibody recognition of a highly conserved influenza virus epitope. Science 324: 246-251. https://doi. org/10.1126/science.1171491

FluSurver (2019) https://flusurver.bii.a-star.edu.sg/

Glezen WP, Paredes A, Taber LH (1980) Influenza in children: relationship to other respiratory agents. JAMA 243: 1345-1349. https://doi.org/10.1001/jama.243.13.1345

Hallmann-Szelińska E, Cieślak K, Kowalczyk D, Szymański K, Brydak LB (2018) Antibodies to influenza virus hemagglutinin in the 2016/2017 epidemic season in Poland. Adv Exp Med Biol 1108: 6974. https://doi.org/10.1007/5584_2018_232

Hallmann-Szelińska E, Szymański K, Luniewska K, Masny A, Kowalczyk D, Sałamatin R, Brydak LB (2019) Occurrence of influenza hemagglutinin antibodies in the Polish population during the epidemic season 2017/18. Adv Exp Med Biol Oct 22. https://doi.org/ 10.1007/5584_2019_443

Houser K, Subbarao K (2015) Influenza vaccines: challenges and solutions. Cell Host \& Microbe 17: 295-300. https://doi.org/10.1016/j. chom.2015.02.012

Izurieta HS, Thompson WW, Kramarz P, Shay DK, Davis RL, DeStefano F, Black S, Shinefield H, Fukuda K (2000) Influenza and the rates of hospitalization for respiratory disease among in- 
fants and young children. N Engl J Med 342: 232-239. https://doi. org/10.1056/NEJM200001273420402

Jang YH, Seong BL (2019) The quest for a truly universal influenza vaccine. Front Cell Infect Microbiol 9: 344. https://doi.org/10.3389/ fcimb.2019.00344

Knowlden ZAG, Richards KA, Moritzky SA, Sant AJ (2019) Peptide epitope hot spots of CD4 $\mathrm{T}$ cell recognition within influenza hemagglutinin during the primary response to infection. Pathogens 8: 220. https://doi.org/10.3390/pathogens8040220

Kondrich J, Rosenthal M (2017) Influenza in children. Curr Opinion Pediatrics 29: 297-302. doi:10.1097/mop.0000000000000495

Kowalczyk D, Szymański K, Cieślak K, Brydak LB (2017) Circulation of antibodies against influenza virus hemagglutinins in the 2014/2015 epidemic season in Poland. Adv Exp Med Biol 968: 3540. https://doi.org/10.1007/5584_2016_191

Kowalczyk D, Szymański K, Cieślak K, Hallmann-Szelińska E, Brydak LB (2019) Circulation of influenza virus in the 2015/2016 epidemic season in Poland: serological evaluation of anti-hemagglutinin antibodies. Adv Exp Med Biol 1150: 77-82. https://doi. org/10.1007/5584_2018_271

Krammer F, Palese P (2013) Influenza virus hemagglutinin stalk-based antibodies and vaccines. Curr Opinion Virol 3: 521-530. https://doi. org/10.1016/j.coviro.2013.07.007

Lin YP, Xiong X, Wharton SA, Martin SR, Coombs PJ, Vachieri SG, Christodoulou E, Walker PA, Liu J, Skehel JJ, Gamblin SJ, Hay AJ, Daniels RS, McCauley JW (2012) Evolution of the receptor binding properties of the influenza A(H3N2) hemagglutinin. Proc Natl Acad Sci USA 109: 21474-21479. https://doi.org/10.1073/ pnas. 1218841110

Neumann G, Noda T, Kawaoka Y (2009) Emergence and pandemic potential of swine-orgine H1N1 influenza virus. Nature 459: $931-$ 939. https://doi.org/10.1038/nature08157
Paules C, Subbarao K (2017) Influenza. Lancet 390: 697-708. https:// doi.org/10.1016/S0140-6736(17)30129-0

Skehel JJ, Wiley DC (2000) Receptor binding and membrane fusion in virus entry: the influenza hemagglutinin. Annu Rev Biochem 69: 531569. https://doi.org/10.1146/annurev.biochem.69.1.531

Sriwilaijaroen N, Suzuki Y (2012) Molecular basis of the structure and function of $\mathrm{H} 1$ hemagglutinin of influenza virus. Proc Jpn Acad Ser. B 88. https://doi.org/10.2183/pjab.88.226

Tyrell DAJ, Horsfall FL (1952) A procedure which eliminates nonspecific inhibitor from human serum but does not affect specific antibodies against influenza viruses. I Immunol 69: 563-574

Webster RG (2013) Textbook of influenza. Wiley Blackwell, ISBN 978-0470-67048-4

WHO - Global Influenza Surveillance Network (2011) Manual for the laboratory diagnosis and virological surveillance of influenza. WHO Press pp 1-153. Geneva

WHO (2018) Recommended composition of influenza virus vaccines for use in the 2018-2019 northern hemisphere influenza season. Available from http://www.who.int/en/

WHO (2019) http://apps.who.int/flumart/Default?ReportNo=12 (Accesed 28.10.2019).

WHO (2019) http://www.euro.who.int/en/health-topics/communicable-diseases/influenza/vaccination/influenza-vaccination-coverage-and-effectiveness (Accesed 31.10.2019)

Vemula SV, Zhao J, Liu J, Wang X, Biswas S, Hewlett I (2016) Current approaches for diagnosis of influenza virus infections in humans. Viruses 8: 96. https://doi.org/10.3390/v8040096 